\title{
Isolation and Characterization of the Dopa Decarboxylase Gene of Drosophila melanogaster
}

\author{
JAY HIRSH $^{1 *}$ AND NORMAN DAVIDSON ${ }^{2}$ \\ Department of Biological Chemistry, Harvard Medical School, Boston, Massachusetts $02115,{ }^{1}$ and \\ Department of Chemistry, California Institute of Technology, Pasadena, California $91125^{2}$
}

Received 23 February 1981/Accepted 30 March 1981

We have isolated chromosomal deoxyribonucleic acid clones containing the Drosophila dopa decarboxylase gene. We describe an isolation procedure which can be applied to other nonabundantly expressed Drosophila genes. The dopa decarboxylase gene lies within or very near polytene chromosome band 37C1-2. The gene is interrupted by at least one intron, and the primary mode of regulation is pretranslational. At least two additional sequences hybridized by in vivo ribonucleic acid-derived probes are found within a 35-kilobase region surrounding the gene. The developmental profile of ribonucleic acid transcribed from one of these regions differs from that of the dopa decarboxylase transcript.

The dopa decarboxylase (DDC) gene of Drosophila melanogaster is of considerable interest for a study of gene regulation. It is a well-characterized genetic locus, and it displays a complex pattern of developmental expression which is hormonally regulated during at least part of the life cycle. We have initiated a study of the structure and expression of this gene using recombinant deoxyribonucleic acid (DNA) techniques.

DDC is an essential enzyme in the pathway of sclerotinization, the process of cuticle tanning and hardening in Drosophila. It is localized primarily in the hypoderm. DDC activity is developmentally regulated, showing major peaks at the time of puparium formation and again at adult eclosion $(22,26)$. The first major peak of enzyme activity parallels a rise in titer of the molting hormone $\beta$-ecdysone $(16,20)$, and the available evidence suggests that $\beta$-ecdysone is required for the appearance of this enzymatic activity $(20,25)$. In contrast, the second major peak of activity, at adult eclosion, is not correlated with an elevated $\beta$-ecdysone titer. This activity, which occurs some $90 \mathrm{~h}$ after pupariation, occurs when $\beta$-ecdysone levels are very low and have been low for some $40 \mathrm{~h}$ (16). Thus, the two major inductions of DDC activity appear to be induced by dissimilar mechanisms.

The DDC structural gene, Ddc, has been localized to a small region consisting of at most seven bands on the left arm of the second chromosome, between bands 37B9 and 37C5 (40; Wright, personal communication). This region contains at least 11 lethal complementation groups and the recessive gene hook (Wright, personal communication). Though most of these genes have no known phenotype, the genes hook and 1(2)amd bear functional relations to $D d c$ (39), suggesting the possibility of clustered, developmentally related genes.

In this study, we report the isolation of chromosomal DNA clones containing the DDC structural gene. DDC ribonucleic acid (RNA) represents only about 0.01 to $0.1 \%$ of Drosophila polyadenylated $\left[\operatorname{poly}(\mathrm{A})^{+}\right]$RNA even at times of maximal DDC expression. It was thus necessary to develop a multistep screening procedure to isolate the gene. Briefly, this involved selection and counterselection of chromosomal clones with complementary DNA (cDNA) probes transcribed from poly $(\mathrm{A})^{+} \mathrm{RNA}$, and a final screening by in situ hybridization. This led to the isolation of one clone hybridizing to the polytene chromosomal region containing $D d c$. That this clone contains the DDC structural gene was shown by selecting complementary RNA (cRNA) with the cloned DNA and demonstrating that the in vitro translation product was the DDC polypeptide.

\section{MATERIALS AND METHODS}

Isolation of DNA and RNA. DNA was isolated from embryos as per Brutlag et al. (9). RNA was isolated from organisms by using a modification of the technique of Chirgwin et al. (11). A 1-g sample of organisms was homogenized with a Teflon-on-glass motor-driven homogenizer in $17 \mathrm{ml}$ of $4 \mathrm{M}$ guanidinium thiocyanate-1 $M \beta$-mercaptoethanol- $0.05 \mathrm{M}$ sodium acetate $(\mathrm{pH} 4.5)-0.001 \mathrm{M}$ ethylenediaminetetraacetate in a fume hood. $\mathrm{CsCl}$ was added at $1 \mathrm{~g} / \mathrm{ml}$ of volume, mixed, and loaded in a Ti60 centrifuge tube. The solution was then underlaid with 0.25 volume of density-1.8 $\mathrm{CsCl}$, containing $0.05 \mathrm{M}$ sodium acetate 
(pH 4.5)-0.001 M ethylenediaminetetraacetate. Tubes were spun for $24 \mathrm{~h}$ at $40,000 \mathrm{rpm}\left(20^{\circ} \mathrm{C}\right)$ in a Ti60 rotor. RNA comigrates with an opalescent band about halfway down the tube and was removed by puncture through the side. Some developmental stages yield more than one visible band (probably carbohydrate). The RNA was diluted with 2 volumes of water, ethanol precipitated, resuspended, and passed through an oligodeoxythymidylate column by the method of Bantle et al. (4).

RNA was isolated from epidermal cells adhering to cuticles after the viscera of the larvae were removed by squashing with a rubber roller $(15 \mathrm{~cm}$ by $2-\mathrm{cm}$ diameter). Clearance between the roller and a glass plate was achieved by strips of 0.007 -in. (ca. $0.18-\mathrm{mm}$ ) electrical tape, laid to form parallel tracks for the roller. About 50 larvae spread evenly near one edge of the plate were run over with heavy arm pressure on the roller. The cuticles were quickly picked off the roller and plate and homogenized immediately in the extraction buffer. Typical increases of three- to fivefold in DDC specific activity were observed in the integumentary fraction relative to the whole larvae, with recovery of 80 to $90 \%$ of the activity in this fraction.

Screening and lambda chromosomal library. We screened the library of Canton-S Drosophila inserts in bacteriophage lambda charon 4 constructed by J. Lauer (23). The screening protocol used was that of Benton and Davis (5), as detailed by Maniatis et al. (23). In the initial screen, $2 \times 10^{4}$ phage on six $150-\mathrm{mm}$ plates were transferred to two filters each. The 12 filters were then hybridized with $60 \mathrm{ng}\left(1.5 \times 10^{7} \mathrm{dpm}\right)$ of cDNA synthesized from sucrose gradient-fractionated cuticular poly $(A)^{+}$RNA as per Efstratiadis et al. (13). Hybridization was for $48 \mathrm{~h}$ at $67^{\circ} \mathrm{C}$ in $65 \mathrm{ml}$. Hybridizing phage were picked with toothpicks into microtiter wells containing $200 \mu$ l of lambda suspension medium in order of decreasing signal intensity. The 350 most intensely hybridizing plaques were plaque purified as follows: the phage were diluted by dipping a stamper of sterile 1/8-in. (ca. 3.18-mm)-diameter prongs into the wells, then into a microtiter plate containing fresh suspension medium. Each such transfer gave a dilution of about 100 -fold. Samples $(20 \mu \mathrm{l})$ of dilutions expected to yield about 50 phage were pipetted onto fresh bacterial lawns on $150-\mathrm{mm}$ plates, in whose surface circles had been impressed with the top of a 1.5-cm-diameter test tube. The impressions of the tube served as pipetting guides. In this manner, 50 different phage could be plated on each plate. At the end of the first such plating, the concentrations of each phage stock were adjusted to give the optimal titer, and the platings were repeated. The phage plaques on these plates were then transferred to filters as before and hybridized with the original probe. This screening resulted in 220 phage with purity greater than $75 \%$.

The phage were screened further by hybridizations to either larval integument or embryo probes. The purified phage, again in microtiter plates, were transferred to two bacterial lawns each, to form an array of "macroplaques," and again transferred to filters. These filters were hybridized with either a size-fractionated integument-derived cDNA probe or a fivefold excess of cDNA synthesized from embryonic RNA. Comparisons of hybridization intensities with each probe revealed 20 plaques which were hybridized more strongly by the larval than by the embryo probe and 25 plaques which hybridized at approximately the same intensity by both probes. These $\mathbf{4 5}$ phage were then grown up individually as plate lysates and combined after growth into six pools. DNA was prepared from each pool by the method of Maniatis et al. (23), and $\left[{ }^{3} \mathrm{H}\right] \mathrm{RNA}$ was synthesized from each pool by the method of Wensink et al. (37). A $2.5 \times 10^{5}$-dpm quantity of RNA was used to hybridize salivary chromosome squashes, essentially as per Bonner and Pardue (7). Hybridizations were carried out in $50 \%$ formamide-0.02 M PIPES [piperazine- $N, N^{\prime}$-bis(2-ethanesulfonic acid)] ( $\mathrm{pH} \mathrm{7.2)-0.1} \mathrm{mM}$ ethylenediaminetetraacetate for $40 \mathrm{~h}$ at $43^{\circ} \mathrm{C}$, in a volume of $10 \mu \mathrm{l}$ per slide. In each hybridization was included $7 \times 10^{5} \mathrm{dpm}$ of cRNA synthesized from a plasmid hybridizing to the chromosomal region 38A (J. Hirsh, unpublished data), which served as a visual marker for the DDC region.

P1 and EK1 recombinant DNA containment conditions were used in this study.

Gel electrophoresis and transfer. DNA fragments were electrophoresed on $0.7 \%$ agarose gels and transferred to nitrocellulose filters by the technique of Southern (34). Hybridization was by the method of Jeffreys and Flavell (17), with specific conditions as given in the figure legends. RNA was chromatographed on $1 \%$ agarose-5 mM methyl mercury gels (3). Transfer was to diazotized cellulose paper (1), and hybridizations were accelerated by using dextran sulfate according to Wahl et al. (36).

Hybrid selections and in vitro translation. $\mathrm{Hy}$ brid selections were performed by the techniques of either Woolford and Rosbash (38) or Ricciardi et al. (30). RNA was translated with a nuclease-treated rabbit reticulocyte lysate (29) purchased from New England Nuclear Corp. After translation at $37^{\circ} \mathrm{C}$ for 60 min, nucleic acids were destroyed by incubation with $1 \mu \mathrm{g}$ each of deoxyribonuclease I and ribonuclease $\mathrm{A}$ at $37^{\circ} \mathrm{C}$ for $10 \mathrm{~min}$. Fluorography (21) was used to visualize the ${ }^{36} \mathrm{~S}$ translation products on one- or twodimensional gels. Immunoprecipitations utilizing Staphylococcus protein A ghosts were by the method of Kessler (19).

Electron microscopic R-loop analysis. R-loops were formed by the method of Kaback et al. (18), using the buffer given by these authors. A 2.5- $\mu \mathrm{g}$ sample of poly(A) ${ }^{+}$RNA was incubated with 50 ng of psoralen cross-linked DNA in a volume of $10 \mu \mathrm{l}$. Incubation was for $16 \mathrm{~h}$ with a sliding temperature from 55 to $45^{\circ} \mathrm{C}$.

\section{RESULTS}

Assay of DDC sequence content by in vitro translation. In vitro translation was used to assay DDC sequence content of developmentally staged RNA preparations. The products of a reticulocyte in vitro translation system directed by larval integumentary poly $(A)^{+}$RNA are displayed on a two-dimensional gel in Fig. 1B. The migration of unlabeled DDC on this gel 




FIG. 1. Two-dimensional gels of purified DDC protein and in vitro translation products. Gels were as per O'Farrell (28), except that $0.1 \%$ sodium dodecyl sulfate was added to the lysis buffer (8). All in vitrotranslated samples were treated with $1 \mu \mathrm{g}$ each of deoxyribonuclease and ribonuclease for $10 \mathrm{~min}$ at system is shown in Fig. 1A, and this position is marked with arrows in Fig. 1B through $D$. Though there was a faint band at the indicated position in Fig. 1B, this gel is not sufficient to identify it as DDC. When this same preparation was immunoprecipitated with antiserum made to purified DDC (Fig. 1C), a prominent band was evident at the DDC position. This band was not observed if preimmune serum was used (data not shown). Figure 1D shows that no DDC was visible after the immunoprecipitation of in vitro translation products directed by 0 - to 20 -h-embryo $\operatorname{poly}(\mathrm{A})^{+}$RNA. Thus, the embryo RNA contains at least 10-fold less translatable DDC RNA than the integumentary RNA, as would be expected from the developmental appearance of DDC. From measurements of immunoprecipitable DDC we estimate that DDC represents no more than $0.1 \%$ of the integumentary RNA translation products. To further enrich for DDC sequences, this RNA was fractionated on a sucrose gradient, and selected fractions were translated. Fractions which directed translation of polypeptides with molecular weights comparable to DDC were pooled and used for the synthesis of a cDNA probe.

Screening the Drosophila lambda library. ${ }^{32}$ P-labeled cDNA, synthesized (13) from RNA sedimenting at 17-18S on sucrose gradients, was used as a hybridization probe to screen a Drosophila melanogaster chromosomal DNA library (23). This library was constructed from randomly sheared DNA, cloned in lambda charon 4 using synthetic $E c o R I$ linkers. Hybridization conditions were such that a sequence represeted at an abundance of $5 \%$ would reach $0.2 \times \mathrm{C}_{0} \mathrm{t}_{1 / 2}$ (see experimental procedures).

$37^{\circ} \mathrm{C}$. The acrylamide dimension utilized a 10 to $16 \%$ linear acrylamide gradient. Size standards were Escherichia coli RNA polymerase (86,000 molecular weight [86K]), catalase (41K), and bovine serum albumin (68K). (A) Purified DDC protein. DDC was purified by the method of Clark et al. (12), through the diethylaminoethyl column step. Though not clearly shown on this figure, minor proteins amounting to about $20 \%$ of the mass of the DDC band were visible on the gel. Material from the preparation displayed on the gel was used for production of antiserum in rabbits. (B) Translation products $\left(3.5 \times{ }^{5}\right.$ cpm) from a reaction directed by larval cuticle poly $(A)^{+}$RNA. Exposure, 85 h. (C) Immunoprecipitation with $D D C$ antiserum, starting with $3.5 \times 10^{5}$ cpm of translation products as shown in (B). Exposure, 575 h. All immunoprecipitations utilized Staphylococcus protein $A$ ghosts according to Kessler (19). (D) Immunoprecipitation with DDC antiserum, starting with $3 \times 10^{5} \mathrm{cpm}$ of translation products from $a$ reaction primed with embryo poly $(A)^{+}$RNA. Exposure, $400 h$. 
Thus, the intensity of hybridization should be largely a function of sequence abundance in the probe. From a total of $2 \times 10^{4}$ phage screened ( $2 \times$ equivalent genomes), 700 gave detectable signals. These plaques were picked into microtiter wells in order of decreasing signal intensity. Only the 300 most intensely hybridizing phage were carried further in the screening. These were plaque purified and rescreened (see experimental procedures), yielding 222 phage clones, each being at least $75 \%$ pure.

To enrich for the DDC clone, we used the following counterselection procedure. The phage stocks, in individual microtiter wells, were transferred to bacterial lawns on which they formed macroplaques. Each lysate was transferred to two bacterial lawns in an identical pattern. The resulting plaques were then transferred to filters, which were hybridized with $\left[{ }^{32} \mathrm{P}\right] \mathrm{cDNA}$ probes made from either size-fractionated larval cuticle or nonfractionated embryo RNA. A fivefold excess of embryo probe was used to compensate for the enrichment of the cuticle probe resulting from the size fractionation. Forty-five plaques which hybridized at least as intensely to the larval cuticle probe as to the embryo probe were selected for further screening. These phage were grown up as individual plate stocks, then grouped into five pools for DNA extraction. $\left[{ }^{3} \mathrm{H}\right] R N A$ was transcribed from each DNA pool with Escherichia coli RNA polymerase (37) and was used for in situ hybridization. Since $D d c$ is located in a region of polytene chromosome bands which is often not well spread, we placed a visual marker on the chromosomes. In each hybridization we included cRNA made from a plasmid which hybridizes in situ near Ddc with cytological location $38 \mathrm{~A}$. This plasmid was isolated by serendipity in a previous study (J. Hirsh, unpublished data). One of the five cRNA probes showed hybridization in the region containing $D d c$. On repeating the in situ hybridization with cRNA from the individual members of this pool, we identified one clone hybridizing exclusively to this region. These results are shown in Fig. 2. The arrows point out the band 37C1-2 over which the hybridization appears centered.

The cloned DNA contains the DDC structural gene. RNA complementary to the cloned DNA was selected by R-looping (38) and, in later experiments, by filter hybridization (30). The selected RNA was then translated in vitro, and the products were analyzed on two-dimensional gels. Figure 3A shows a fluorogram from a control reaction (minus DNA), and Fig. 3B shows the translation products of the R-loop selected RNA. The arrow shows the migration

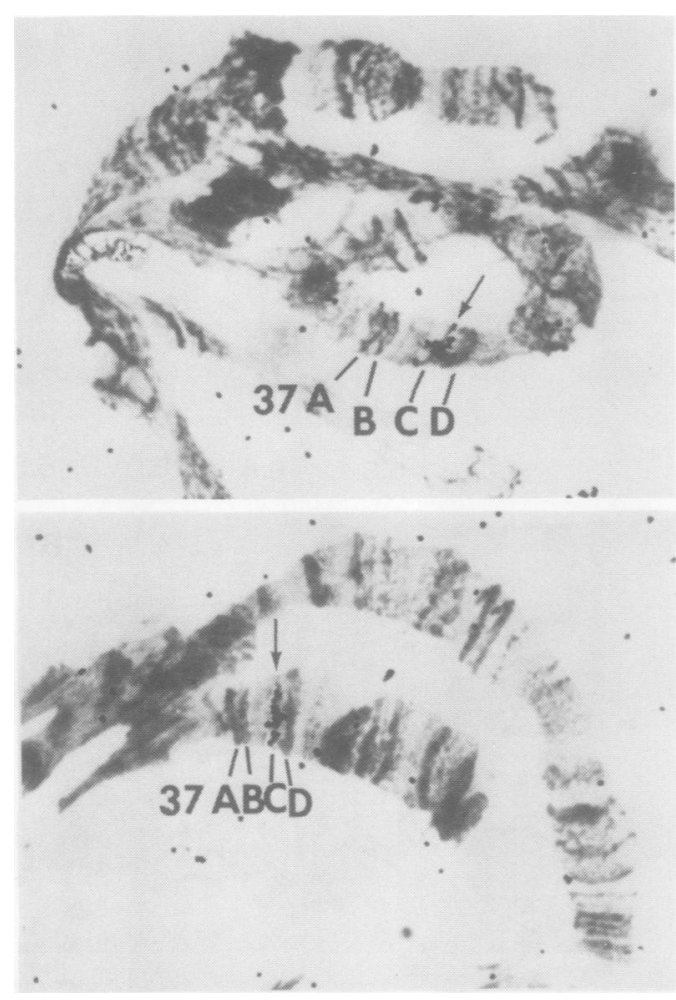

Fig. 2. In situ hybridizations. Detail of the $37 C$ hybridization. The arrows point out the band 37C1-2. The grains over the $38 \mathrm{~A}$ region are due to a marker plasmid included in the hybridizations (see text).

position of DDC. Both gels show a heavy smeared band migrating at about 50,000 molecular weight $(50 \mathrm{~K})$ which is an endogenous translation product, but only Fig. 3B shows a band at the DDC position. Note that the smearing is similar, but even more extreme than that shown in Fig. 1 for unlabeled or immunoprecipitated DDC. This extreme smearing is characteristic of authentic DDC when cochromatographed with the in vitro translation system components (not shown). Figure 4 shows that the hybrid-selected and translated polypeptide is immunoprecipitated by DDC antiserum. Note that the preimmune serum precipitates a small amount of DDC. We consider it unlikely that this low level of immunoprecipitation is specific. Nonspecific adsorption of many Drosophila polypeptides with preimmune serum has been previously observed by G. P. Kraminsky (Masters thesis, University of Alberta, Edmonton, Alberta, Canada, 1980).

Characterization of the cloned DDC DNA. Figure 5 shows restriction sites in the Drosophila DNA of $\lambda \mathrm{Ch} 4 \mathrm{DmDDC}-1$ (or more 


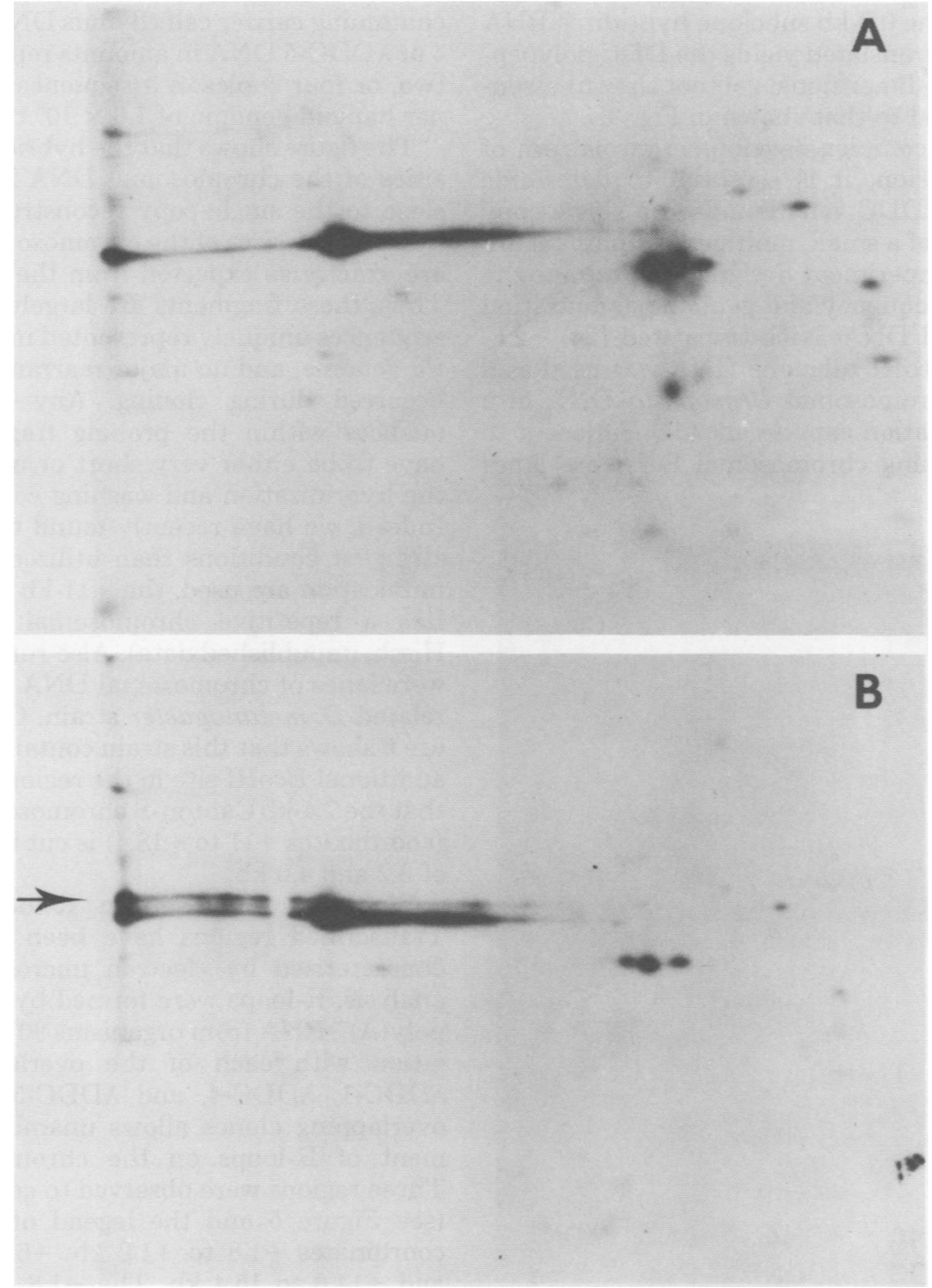

FIG. 3. Two-dimensional gels of $R$-loop selected $R N A$-directed translations (28). A 2.5- $\mu g$ sample of poly $(A)^{+}$ larval cuticle RNA was hybridized with $5 \mu \mathrm{g}$ of $\lambda D D C-1$ DNA (B), or no DNA as a control (A). Hybridizations were for $3 \mathrm{~h}$ at $55^{\circ} \mathrm{C}$ in $20 \mu \mathrm{l}$ of $70 \%$ formamide-0.5 M NaCl-0.1 M PIPES (pH 7.2)-0.01 M ethylenediaminetetraacetate. The reactions were then passed over a 3-ml agarose A-150 M column to separate hybrids from unbound RNA. Exposure, $68 \mathrm{~h}$.

simply, $\lambda D D C-1)$ for the restriction enzymes EcoRI, BamHI, and HindIII, determined by standard techniques of partial and double digestion. Also shown are the EcoRI and BamHI maps of overlapping clones isolated from the lambda library by using the outer $\lambda D D C-1$ EcoRI fragments as probes, and the chromosomal DNA map derived from the cloned DNA.

The left insert endpoint of $\lambda$ DDC- 1 is used as a reference point for other chromosomal positions. Positions to the right of this site (as shown in Fig. 5) are considered positive, and positions to the left are considered negative. Many of the $E$ coRI fragments of $\lambda D D C-1, \lambda D D C-4$, and $\lambda D D C-5$ have been subcloned into the plasmid vector pBR322 (6). The EcoRI subclones are named by the position of their left endpoint, i.e., the subclone containing the 3.0-kilobase (kb) $E c o R I$ fragment covering coordinates 0.0 to +3.0 will be referred to as the $0.0-\mathrm{kb} E$ coRI subclone.

The DDC transcript has been mapped by hybrid selecting RNA with the $\lambda$ DDC-1 EcoRI 
subclones. The 0.0-kb subclone hybridizes RNA which when translated yields the DDC polypeptide on a two-dimensional gel (not shown) essentially identical to that shown in Fig. 3B.

Given the complex developmental pattern of DDC expression, it is essential to determine whether the DDC gene is indeed a single-copy gene or part of a small, multigene family. Figure 6 shows an experiment designed to examine the reiteration frequency and genomic organization of the cloned DNA. Nick-translated (24) -2.5or +11-kb EcoRI subclone DNA was used as a probe for chromosomal Drosophila DNA in a blot hybridization experiment (34). Adjacent to lanes containing chromosomal DNA are lanes

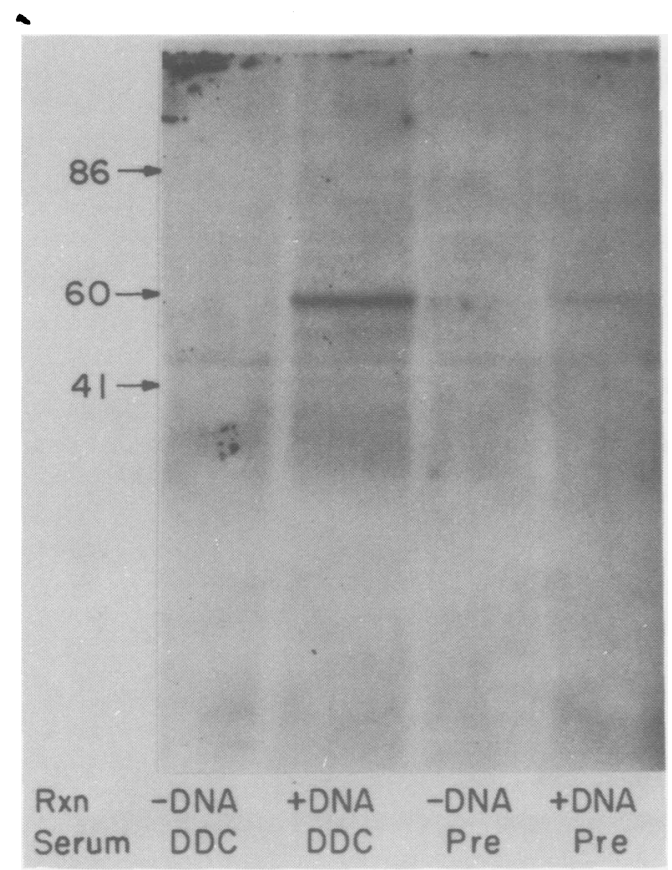

FIG. 4. Immunoprecipitations of the R-loop selected translation products. One-quarter volume of each translation reaction as shown in Fig. 3 was immunoprecipitated with the indicated antiserum. Exposure, $280 h$. containing carrier calf thymus DNA and $\lambda D D C$ 4 or $\lambda$ DDC-5 DNA in amounts representing one, two, or four copies of a sequence of this length per haploid genome of $1.6 \times 10^{8}$ base pairs (32).

The figure shows that the hybridization intensities of the chromosomal DNA lanes are very close to the single-copy reconstruction intensities, and the sizes of the chromosomal fragments are exactly as expected from the cloned DNA. Thus, these fragments are largely composed of sequences uniquely represented in the Drosoph. ila genome, and no major rearrangements have occurred during cloning. Any repetitive sequences within the probing fragments would have to be either very short or unstable under the hybridization and washing conditions used. Indeed, we have recently found that when less stringent conditions than utilized in this communication are used, the $+11-\mathrm{kb}$ probe hybridizes a repetitive chromosomal sequence (J. Hirsh, unpublished data). Also run on these gels were lanes of chromosomal DNA from a closely related $D$. melanogaster strain, Oregon-R. Figure 6 shows that this strain contains at least one additional $E c o R I$ site in the region probed, such that the 7.4-kb Canton-S chromosomal fragment (coordinates +11 to +18.4 ) is cut into fragments of 3.2 and $4.0 \mathrm{~kb}$.

Electron microscopic R-loop analysis. Transcribed regions have been localized and characterized by electron microscopic R-loop analysis. $R$-loops were formed by incubation of poly(A) ${ }^{+}$RNA from organisms $90 \mathrm{~h}$ after pupariation with each of the overlapping clones $\lambda D D C-1, \lambda D D C-4$, and $\lambda D D C-5$. The use of overlapping clones allows unambiguous placement of R-loops on the chromosomal map. Three regions were observed to contain $\mathrm{R}$-loops (see Figure 5 and the legend of Figure 7) at coordinates -1.8 to $+1.0 \mathrm{~kb},-6.2$ to $-5.1 \mathrm{~kb}$, and +14.6 to $15.4 \mathrm{~kb}$. The -1.8 to $+1.0-\mathrm{kb} \mathrm{R}$ loop must result from the DDC RNA, as this is the only R-loop to overlap the 0.0-kb EcoRI fragment which hybrid-selected DDC RNA. DDC gene R-loops were also formed by hybridizing late third-instar $(115-h)$ larval poly $(A)^{+}$

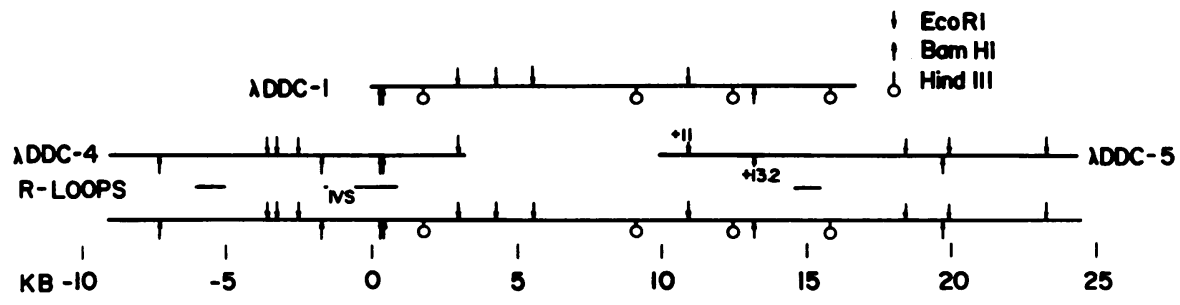

FIG. 5. Restriction maps of chromosomal lambda clone inserts and locations of transcripts. The bottom line shows a continuous map of chromosomal sequences. Transcribed regions identified by electron microscopic R-loop analysis are indicated. The HindIII sites in $\lambda D D C-4$ and $\lambda D D C-5$ are not shown. The lambda arms are oriented $\lambda L-D m-\lambda R$ in $\lambda D D C-1$ and $\lambda D D C-4$, and $\lambda R-D m-\lambda L$ in $\lambda D D C-5$. 


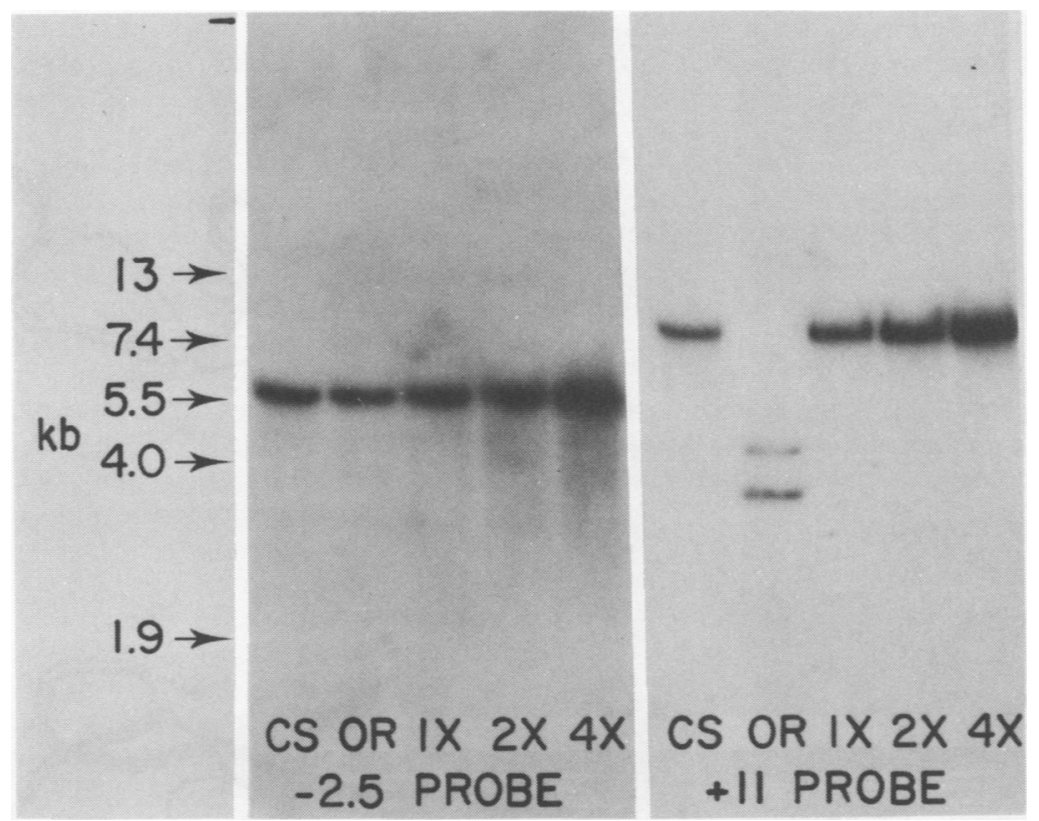

Fig. 6. Genomic blot and reconstructions, hybridized with nick-translated $-2.5-k b$ or $+11-k b$ subclone

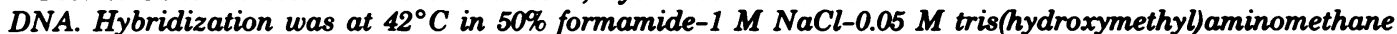

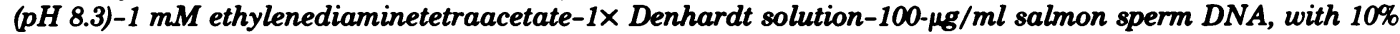

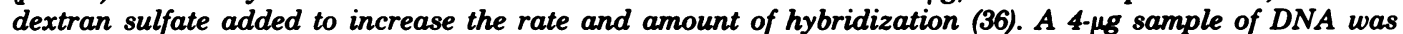
loaded per lane. CS, Canton-S chromosomal DNA. OR, Oregon-R chromosomal DNA. $1 \times, 2 \times$, and $4 \times$ are lanes of calf thymus DNA to which have been added ADDC-4 DNA in amounts equivalent to one, two, or four copies per haploid genome.

RNA with the -2.5-kb EcoRI subclone DNA. The DNA was linearized before hybridization by digestion with the restriction enzyme BglII, which cleaves the DNA at genomic coordinate $+2.3 \mathrm{~kb}$. Six of the 32 observed DDC R-loops that are formed on $\lambda D D C-4$, and 10 of the $30 \mathrm{R}$ loops formed on the subclone, contain a duplex loop interpretable as a 0.9 - to $1.0-\mathrm{kb}$ intron. Examples of intron-containing DDC R-loops from both hybridizations are shown in Fig. 7, and the data derived from these hybridizations are summarized in the figure legend. The hybridizations with both RNA species show the DDC gene to contain a 0.9 - to $1.0-\mathrm{kb}$ intervening sequence, flanked by a 1.6- to $1.7-\mathrm{kb}$ exon and a small exon of 0.1 to $0.3 \mathrm{~kb}$. The data do not show any statistically significant differences in sizes or positions of the R-loops formed by the developmentally different RNA species. The subclone R-loops allow a more precise placement of DDC RNA on the DNA, indicating that the RNA hybridizes to DNA between chromosomal coordinates -1.65 and $+1.25 \mathrm{~kb}$.

Developmental expression of $\lambda$ DDC-1 cRNA. We have made a survey of the developmental expression of RNA complementary to $\lambda D D C-1$ DNA. Figure 8 shows an RNA blot (1) in which equal amounts of $\operatorname{poly}(\mathrm{A})^{+}$cellular
RNA from the indicated developmental stages were subjected to gel electrophoresis, transferred to diazobenzyloxymethyl paper, and hybridized with a nick-translated probe consisting of the 0.0 and +11-kb EcoRI subclones. Also shown are DDC specific activities from each stage from which the RNA was isolated. The DDC activity profiles show the expected activity at pupariation and adult eclosion $(22,26)$. A prior experiment utilizing separated probes showed that the 0.0-kb DDC gene-containing probe hybridized two RNA species migrating with lengths 2.1 and $3.2 \mathrm{~kb}$ and that the $+11-\mathrm{kb}$ probe hybridized a $0.8-\mathrm{kb}$ RNA. The length of $2.1 \mathrm{~kb}$ is in agreement with that measured by electron microscopy for the DDC RNA, and 0.8 $\mathrm{kb}$ is the expected length of the RNA observed to form R-loops at $+15 \mathrm{~kb}$. Levels of the 2.1-kb DDC RNA varied such that high levels were present before pupariation $(115 \mathrm{~h})$ and also before adult eclosion $(200 \mathrm{~h})$. At both of these developmental stages, DDC levels were high and probably were increasing. Only low levels of the 2.1-kb DDC RNA were present at developmental stages when low levels of DDC activity were detectable, or when activity levels were decreasing, such as at $140 \mathrm{~h}$. These results exclude translational and post-translational mechanisms 


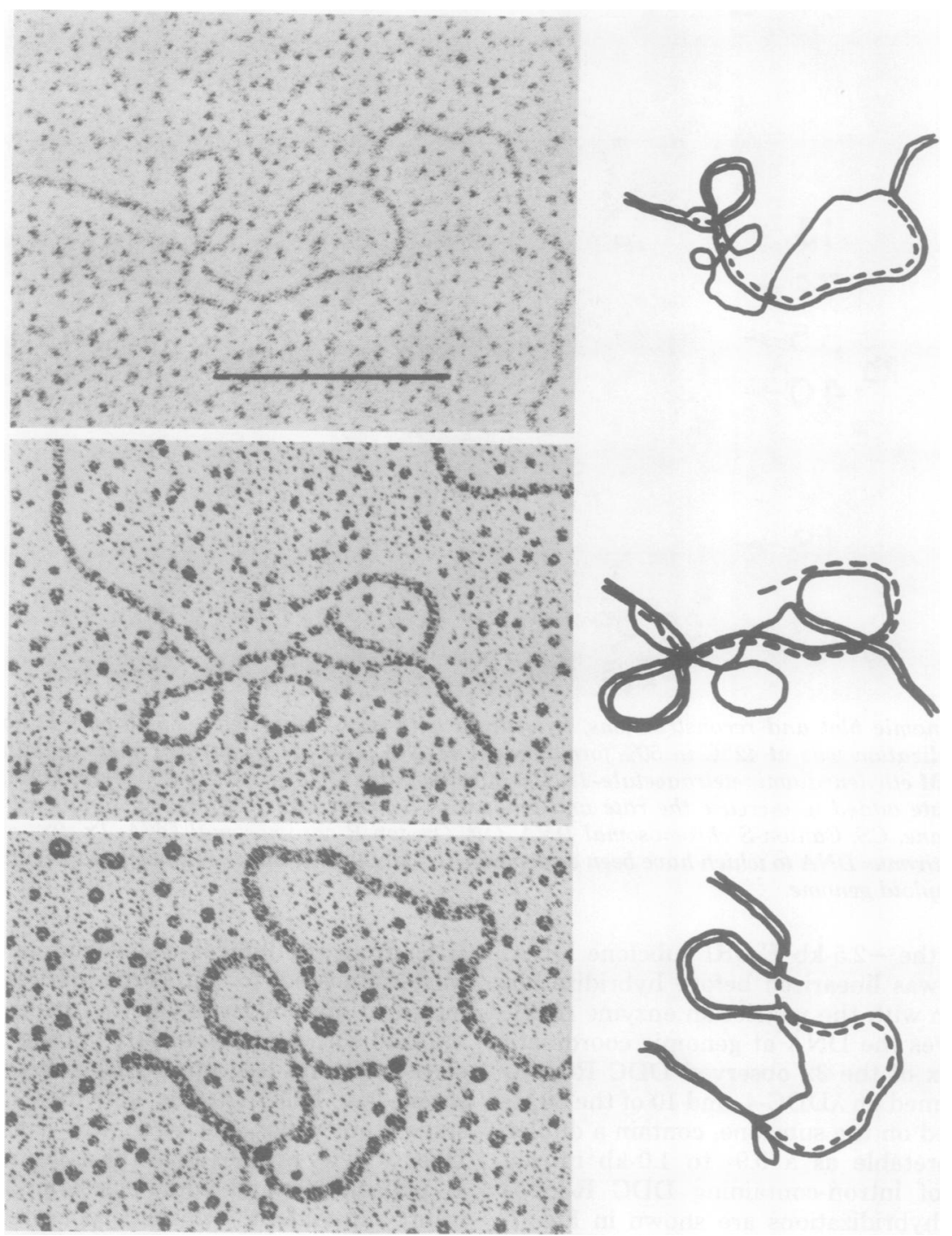

Fig. 7. $D D C R$-loops showing the intron and both exons. The bar represents $1 \mathrm{~kb}$ for all plates. The top plate shows a DDC R-loop formed by hybridizing preadult eclosion RNA with $\lambda 4$ DNA. Data from this hybridization are tabulated as follows. (i) DDC R-loops: center of major exon at coordinate $0.1 \pm 0.21 \mathrm{~kb}(\mathrm{n}$ = 32); length of major exon, $1.72 \pm 0.13 \mathrm{~kb}(n=32)$; frequency, $0.19 R$-loops per DNA molecule. (ii) $D D C R$ loops with an interpretable intervening sequence loop: length of intervening sequence loop, $0.90 \pm 0.07 \mathrm{~kb}(\mathrm{n}$ $=6)$; length of major exon, $1.74 \pm 0.05 \mathrm{~kb}$; length of shorter exon, $0.16 \pm 0.02 \mathrm{~kb}(n=3)$. (iii) $R$-loops centered $a t-5.6 \pm 0.16 \mathrm{~kb}(n=15)$ : length, $1.07 \pm 0.17 \mathrm{~kb}(n=15) ;$ frequency, 0.20 . (iv) $R$-loops centered at $+15.0 \mathrm{~kb} \pm$ $0.17 \mathrm{~kb}(n=27)$ : length, $0.78 \pm 0.04 \mathrm{~kb}(n=27)$; frequency, 0.09. The center and lower photographs show $D D C$ $R$-loops formed by hybridization of late third-instar (115-h) larval poly $(A)^{+}$RNA with subcloned DNA containing the 5.5-kb EcoRI fragment (left edge at coordinate -2.5). Ten of $30 R$-loops observed contained interpretable intervening sequence loops. Data derived from these 10 molecules are as follows: length of major exon, $1.60 \pm 0.06 \mathrm{~kb}$; length of intervening sequence, $1.02 \pm 0.05 \mathrm{~kb}$; length of shorter exon $(n=4), 0.28 \pm 0.09$ $\mathrm{kb}$; center of major exon, $0.45 \pm 0.20 \mathrm{~kb}$. Indicated uncertainties are standard error of the mean for the number (n) of molecules given in parentheses.

tory points in DDC gene expression. The lane on the far right of Fig. 8 shows hybridization to a 115-h larval integumentary RNA, with an exposure time $40 \%$ that of the other lanes. This lane shows several-fold higher levels of DDC RNA than the corresponding 115-h larval RNA lane, indicating that the localization of DDC enzyme activity to the integument results from 

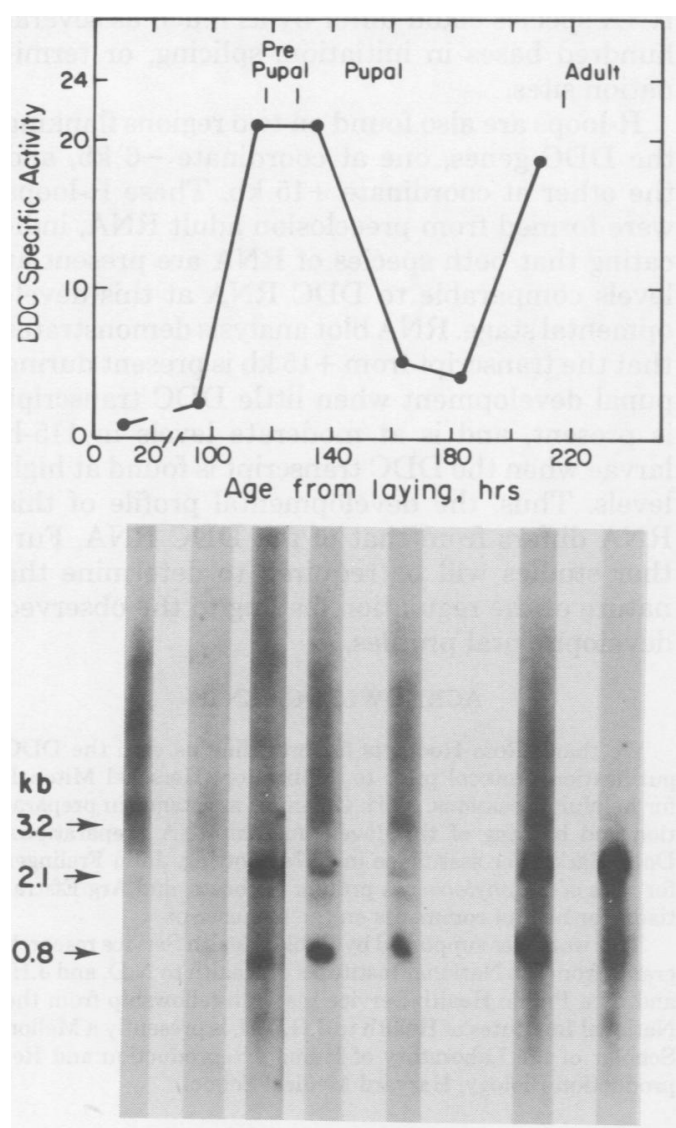

Integument $\times 0.4$

Fig. 8. Northern blot of staged poly $(A)^{+}$RNA and $D D C$ specific activity at each stage. Organisms were staged by taking a 4-h laying and staged again at the third-instar larval stage by taking an 8-h collec-

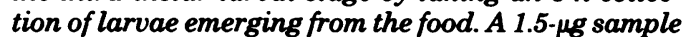
of $\operatorname{poly}(A)^{+}$RNA was loaded per lane. The different $R N A$ preparations gave different saturation yields of oligodeoxythymidylate-primed cDNA. We assume that this reflects differing fractional poly(A) content, and we adjusted the amount of RNA loaded accordingly. The blot was hybridized with nick-translated 0.0 - and $+11-k b$ subclone DNA. Size standards were single-strand DNA. Hybridization was with dextran sulfate as in Fig. 6. The lane of hybridization on the far right is to $1.5 \mu \mathrm{g}$ of integumentary poly $(A)^{+}$RNA from 115.h larvae, exposed $40 \%$ as long as the other lanes. $D D C$ specific activity is expressed as nanomoles of dopamine per 20 min per milligram of protein at $30^{\circ} \mathrm{C}$, using the assay of McCaman et al. (26).

increased levels of DDC RNA.

Levels of the 0.8-kb RNA do not vary in parallel with the 2.1-kb DDC RNA, though some similarities in developmental profiles are apparent. Both species begin to appear at moderate levels in 115-h larvae and are present at high levels in preeclosion adults. Levels of the $0.8-\mathrm{kb}$ RNA, however, do not parallel levels of the 2.1kb DDC RNA during pupal development. Our results do not preclude, however, some common step in the regulation of both transcripts.

The nature of the faint $3.2-\mathrm{kb}$ band hybridized by the $0.0-\mathrm{kb}$ probe is unknown, though its length is close to the expected size of a precursor molecule of the mature DDC RNA.

\section{DISCUSSION}

We have isolated chromosomal DNA clones containing the Drosophila melanogaster Ddc gene. We describe a procedure for isolating the gene from a chromosomal library which will be applicable to the isolation of other cytogenetically localized Drosophila genes with nonabundant transcripts for which antibodies or other means of protein identification are available. Since the gene is maximally expressed as only about 0.01 to $0.1 \%$ of the poly $(A)^{+}$RNA, we utilized multistep screening, involving selection and counterselection with RNA derived probes, followed by in situ hybridization.

The extensive background of genetic, physiological, and biochemical studies on this gene and its enzyme product suggest that the cloned DNA will be useful for studying many aspects of DDC expression. $D d c$ lies within a chromosomal region which appears to contain many genes. Near $D d c$ lie two characterized genes, 1(2)amd and hook, both of which appear to bear developmental relations to Ddc. Mutant alleles of the 1(2)amd locus, designated amdH, show increased sensitivity to $\alpha$-methyl dopa, an inhibitor of DDC, without altering in any detectable manner the sensitivity of DDC to the inhibitor or the levels of DDC activity $(12,35,39)$. 1(2)amd maps extremely close to $D d c$, perhaps within a few thousand base pairs (39). The other gene, hook, leads to hooked bristles (27). This phenotype is of interest because bristles are formed from differentiated hypodermal cells and are themselves sclerotinized. We consider it an attractive possibility that one of the additional transcribed sequences we have found near the DDC gene corresponds to 1(2)amd. Screening of 1(2)amd mutants induced so as to yield rearrangement breakpoints affecting the gene should give evidence on this point.

In addition to these three genes, Wright (personal communication) found at least nine other genes, so far identified only as lethal complementation groups, mapping with the same boundaries as $D d c$, between the polytene chromosome bands 37B9 and 37C5 (40; Wright, personal communication). If a polytene chromosome band of average density contains about 30 
kb of DNA (31), we expect the seven bands within this region to contain about $210 \mathrm{~kb}$ of DNA. However, since six of the seven bands are very faint (33), and since the cytogenetics has defined only the outer limits for the region, we expect that the region contains even less DNA. In any case, the evidence suggests a dense clustering of genes in a region small enough to be studied by recombinant DNA techniques.

Our in situ hybridization data localize $D d c$ to lie in or very close to the band $37 \mathrm{C} 1-2$. This band has not been observed to puff during late larvalprepupal development (2).

DDC gene expression is developmentally regulated, with major peaks of DDC activity at the time of pupariation and again at adult eclosion $(15,22,26)$. The appearance of DDC activity at pupariation is dependent on the molting hormone $\beta$-ecdysone. This has been shown in closely related dipterans $(10,14)$ and in Drosophila by utilizing temperature-sensitive $\beta$-ecdysone synthesis mutants $(20,25)$. Kraminsky et al. (20) show that the induction of DDC by exogenously fed $\beta$-ecdysone is rather rapid, occurring within $2 \mathrm{~h}$. In contrast, the preeclosion response is not correlated with elevated $\beta$-ecdysone titers and may be induced by other factors. The availability of probes specific for DDC transcripts and of the genomic DNA sequences to which regulatory proteins must bind will be of value in dissecting these mechanisms of expression. Our measurements of the developmental expression of DDC transcripts demonstrate that DDC RNA levels vary through development, as would be expected if the rate of DDC synthesis were related to the amount of RNA present. This indicates that the major regulatory points of DDC expression at pupariation and adult eclosion are pretranslational. Our results confirm and extend the findings of Kraminsky et al. (20), who show that levels of translatable DDC RNA increase at pupariation.

R-loop analysis shows that the DDC gene contains an intron near one end of the RNA. The large exon measures 1.6 to $1.7 \mathrm{~kb}$. The intron has a length of 0.9 to $1.0 \mathrm{~kb}$ and occurs within about 300 bases of the $5^{\prime}$ end of the RNA (Hirsh, unpublished data). Tails of poly(A) or displaced RNA seen on many of the R-loops indicate that the actual length of the transcript may be slightly larger. In agreement with this inference, RNA blot hybridization analysis indicates a length of $2.1 \mathrm{~kb}$ for the transcript.

R-loops formed with RNA from two developmental stages, late (115-h) third-instar larvae or preeclosion adults, have not shown any significant differences in R-loop sizes or positions on the DNA. Since the errors in these measurements are rather large, it is still possible that the
RNA species could differ by as much as several hundred bases in initiation, splicing, or termination sites.

R-loops are also found on two regions flanking the DDC genes, one at coordinate $-6 \mathrm{~kb}$, and the other at coordinate $+15 \mathrm{~kb}$. These R-loops were formed from preeclosion adult RNA, indicating that both species of RNA are present at levels comparable to DDC RNA at this developmental stage. RNA blot analysis demonstrates that the transcript from $+15 \mathrm{~kb}$ is present during pupal development when little DDC transcript is present, and is at moderate levels in 115-h larvae when the DDC transcript is found at high levels. Thus, the developmental profile of this RNA differs from that of the DDC RNA. Further studies will be required to determine the nature of the regulation leading to the observed developmental profiles.

\section{ACKNOWLEDGMENTS}

We thank Ross Hodgetts for providing us with the DDC purification protocol prior to publication, Herschel Mitchell for helpful discussions, Y. H. Chien for assistance in preparation and blotting of the developmental RNA preparations, Doug Barker for assistance in DNA blotting, John Frelinger for gifts of Staphylococcus protein A ghosts, and Arg Efstratiadis for helpful comments on the manuscript.

This work was supported by Public Health Service research grants from the National Institutes of Health to N.D. and J.H. and by a Public Health Service research fellowship from the National Institutes of Health to J.H. J.H. is presently a Mellon Scholar of the Laboratory of Human Reproduction and Reproduction Biology, Harvard Medical School.

\section{LTTERATURE CITED}

1. Alwine, J. C., D. J. Kemp, and G. R. Stark. 1977. Method for detection of specific RNAs in agarose gels by transfer to diazobenzyloxymethyl paper and hybridization with DNA probes. Proc. Natl. Acad. Sci. U.S.A. 74:5350-5354.

2. Ashburner, M. 1978. Pattern of puffing activity in the salivary gland chromosomes of Drosophila. VIII. A revision of the puffing patterns of the proximal region of chromosome arm 2L of D. Melanogaster. Chromosoma 68:195-203.

3. Bailey, J. M., and N. Davideon. 1976. Methyl mercury as a reversible denaturing agent for agarose gel electrophoresis. Anal. Biochem. 70:75-85.

4. Bantle, J. A., I. H. Maxwell, and W. E. Hahn. 1976. Specificity of oligo dT-cellulose chromatography in the isolation of polyadenylated RNA. Anal. Biochem. 72: 413-427.

5. Benton, W. D., and R. W. Davis. 1977. Screening $\lambda$ gt recombinant clones by hybridization to single plaques in situ. Science 196:180-182.

6. Bolivar, F., R. L. Rodriguez, P. J. Greene, M. D. Betlach, H. L. Heyneker, H. W. Boyer, J. H. Crosa, and S. Falkow. 1977. Construction and characterization of new cloning vehicles. II. A multi-purpose cloning system. Gene 2:95-113.

7. Bonner, J. J., and M. L. Pardue. 1976. Ecdysone-stimulated RNA synthesis in imaginal discs of Drosophila melanogaster. Chromosoma 68:87-99.

8. Brandhorst, B. P. 1976. Two dimensional gel patterns of protein synthesis before and after fertilization of sea urchin eggs. Dev. Biol. 52:310-317. 
9. Brutlag, D., R. Appels, E. S. Dennis, and W. J. Peacock. 1977. Highly repeated DNA in Droeophila melanogaster. J. Mol. Biol. 112:31-47.

10. Chen, T. T., and R. B. Hodgetts. 1974. The appearance of dopa decarboxylase activity in imaginal discs of Sarcophaga bullata, undergoing development in vitro. Dev. Biol. 38:271-284.

11. Chirgwin, J. M., A. E. Pryybyla, R. J. MacDonald, and $W$. J. Rutter. 1979. Isolation of biologically active ribonucleic acid from sources enriched in ribonuclease. Biochemistry 18:5294-5299.

12. Clark, W. C., P. S. Pass, V. Bhagyalakshmi, and R. B. Hodgetts. 1978. Dopa decarboxylase from Drosophila melanogaster. purification, characterization and analysis of mutants. Mol. Gen. Genet. 162:287-297.

13. Efstratiadis, A., T. Maniatis, F. C. Kafatos, A. Jeffrey, and J. N. Vournakis. 1975. Full length and discrete partial reverse transcripts of globin and chorion mRNAs. Cell 4:367-378.

14. Fragoulis, E. G., and C. E. Sekeris. 1975. Translation of mRNA for 3,4-dihydroxyphenylalanine decarboxylase isolated from epidermal tissue of Calliphora vicina R.-D. in an heterologous system. Eur. J. Biochem. 51: 305-316.

15. Hodgetts, R. B. 1975. The response of dopa decarboxylase activity to gene dosage in Drosophila: a possible location of the structural gene. Genetics 79:45-54.

16. Hodgetts, R. B., B. Sage, and J. D. O'Connor. 1977. Ecdysone titers during postembryonic development of Droeophila melanogaster. Dev. Biol. 60:310-317.

17. Jeffreys, A. J., and R. A. Flavell. 1977. The rabbit $\beta$ globin gene contains a large insert in the coding sequence. Cell 12:1097-1108.

18. Kaback, D. B., L. M. Angerer, and N. Davideon. 1979. Improved methods for the formation and stabilization of $R$ loops. Nucleic Acids Res. 6:2499-2517.

19. Kessler, S. W. 1976. Cell membrane antigen isolation with the staphylococcal protein A-antibody adsorbent. J. Immunol. 117:1482-1490.

20. Kraminsky, G. P., W. C. Clark, M. A. Estelle, R. D. Giets, B. A. Sage, J. D. O'Connor, and R. B. Hodgette. 1980. Induction of translatable mRNA for dope decarboxylase in Drosophila: an early response to ecdysterone. Proc. Natl. Acad. Sci. U.S.A. 77:4175-4179.

21. Laskey, R. A., and A. D. Mills. 1975. Quantitative film detection of ${ }^{3} \mathrm{H}$ and ${ }^{14} \mathrm{C}$ in polyacrylamide gels by fluorography. Eur. J. Biochem. 66:335-341.

22. Luman, K. D., and H. K. Mitchell. 1969. The metabolism of tyrosine-0-phosphate in Droeophila. Arch. Biochem. 132:450-456.

23. Maniatis, T., R. C. Hardison, E. Lacy, J. Lauer, C. O'Connell, D. Quon, G. K. Sim, and A. Ffotratiadis. 1978. The isolation of structural genes from libraries of eucaryotic DNA. Cell 15:687-701.

24. Maniatis, T., A. Jeffrey, and D. G. Kleid. 1975. The nucleotide sequence of the rightwand operator of phage ג. Proc. Natl. Acad. Sci. U.S.A. 72:1184-1188.

25. Marsh, J. L, and T. R. F. Wright. 1980. Developmental relationship between dopa decarboxylase, dopamine acetyl transferase, and ecdysone in Drosophila. Dev. Biol. 80:379-387.

26. McCaman, M. W., R. E. McCaman, and G. J. Lees. 1972. Liquid cation exchange-a basis for sensitive radiometric assays for aromatic amino acid decarboxylases. Anal. Biochem. 45:242-252.

27. Mitchell, H. K., and L. S. Lipps. 1978. Heat shock and phenocopy induction in Droeophila. Cell 16:907-918.

28. O'Farrell, P. H. 1975. High resolution two-dimensional electrophoresis of proteins. J. Biol. Chem . 250:40074021.

29. Pelham, H. R. B., and R. J. Jackson. 1976. An efficient mRNA-dependent translation system from reticulocyte lysates. Eur. J. Biochem. 67:247-256.

30. Ricciardi, R. P., J. S. Miller, and B. E. Roberts. 1979. Purification and mapping of specific $m$ RNAs by hybridization-selection and cell free translation. Proc. Natl. Acad. Sci. U.S.A. 76:4927-4931.

31. Rudlin, G. T. 1965. The relative mutabilities of DNA in regions of the $\mathrm{X}$ chromosome of Drosophila melanogaster. Genetics 52:665-681.

32. Rudlin, G. T. 1972. Replication in polytene chromosomes, p. 59-85. In W. Beerman (eds.), Results and problems in cell differentiation, vol. 4. Springer-Verlag, New York.

33. Saura, A. O., and V. Sorsa. 1979. Electron microscopic analysis of the banding pattern in the salivary glands of Drosophila melanogaster: divisions 37,38 and 39 of $2 \mathrm{~L}$. Heriditas 91:5-18.

34. Southern, E. M. 1975. Detection of specific sequences among DNA fragments separated by gel electrophoresis. J. Mol. Biol. 98:503-517.

35. Sparrow, J. C., and T. R. F. Wright. 1974. The selection for mutants in Drosophila melanogaster hypersensitive to $\alpha$-methyl dopa, a dopa decarboxylase inhibitor. Mol. Gen. Genet. 130:127-141.

36. Wahl, G. M., M. Stern, and G. R. Stark. 1979. Efficient transfer of large DNA fragments from agarose gels to diazobenzyloxymethyl paper and rapid hybridization using dextran sulfate. Proc. Natl. Acad. Sci. U.S.A. 76: 3683-3687.

37. Wensink, P. C., D. J. Finnegan, J. E. Donelson, and D. S. Hogness. 1974. A system for mapping DNA sequences in the chromosomes of $\mathrm{D}$. melanogaster. Cell 3:315-325.

38. Woolford, J. L, and M. Rosbash. 1979. The use of Rlooping for structural gene identification and mRNA purification. Nucleic Acids Res. 6:2483-2498.

39. Wright, T. R. F., G. C. Bewley, and A. F. Sherald. 1976. The genetics of dopa decarboxylase in Drosophila melanogaster. II. Isolation and characterization of dopa decarboxylase mutants and their relationship to the $\alpha$ methyl dopa hypersensitive mutants. Genetics 84:287310.

40. Wright, T. R. F., R. B. Hodgetts, and A. F. Sherald. 1976. The genetics of dopa decarboxylase in Drosophila melanogaster. I. Isolation and characterization of the structural locus and the $\alpha$-methyl dopa hypersensitive locus. Genetics 84:267-285. 